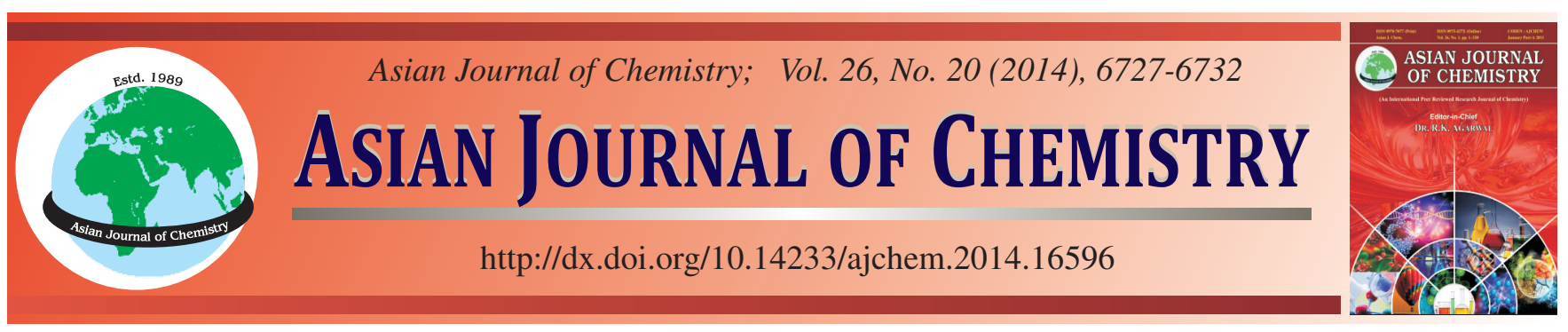

\title{
Effect of Biological Pretreatment of Water Hyacinth on Enzymatic Hydrolysis for Bioethanol Production
}

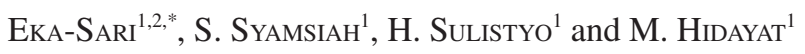

${ }^{1}$ Chemical Engineering Department, Gadjah Mada University, Yogyakarta, Indonesia

${ }^{2}$ Chemical Engineering Department, Sultan Ageng Tirtayasa University, Cilegon-Banten, Indonesia

*Corresponding author: Tel : +62 81802759810,E-mail: ekasari_gt@yahoo.com; ekasari@untirta.ac.id

\begin{abstract}
The key to success in increasing the glucose yield lies in the need to optimize the pretreatment process. The expectation is that lignocellulosic materials will be more easily hydrolyzed by the cellulase enzymes and produce a high yield of glucose. To improve the digestibility of water hyacinth in the enzymatic hydrolysis process and improve glucose production release, it is necessary to optimize of a pretreatment process. We evaluated the effects of varying biological pretreatment process conditions such as initial moisture content (IMC), material size, the addition of molasses and $\mathrm{Co}$-factor $\mathrm{Mn}^{2+}$ for lignin degradation and the glucose production The results showed that choosing a $70 \%$ IMC can provide increased yields of glucose reached $16.87 \%$. Selecting material size provides a glucose yield enhancement of $20.02 \%$. To prevent the degradation of cellulose in the pretreatment process the addition of molasses at a concentration of $2 \%$ gave encouraging results, with the glucose yield reaching $43.91 \%$. Further, addition of co-factor $\mathrm{Mn}^{2+}$ using a concentration of $0.5 \%$ significantly increased the yield of glucose, which reached $66.67 \%$ during 16 days of incubation.
\end{abstract}

Keywords: Pretreatment, Phanerochaete chrysosporium, Degradation, Lignin, Water hyacinth.

\section{INTRODUCTION}

Energy crisis and environmental pollution is a serious problem posed by the use of fossil fuels. Therefore, it is necessary to obtain alternative energy. Bioethanol is one of the alternative energy to replace fossil fuels for transportation purposes ${ }^{1}$. Previously, bioethanol is produced from the fermentation of sugar or starch materials. It is feared could lead to food crisis. Therefore, bioethanol began to be produced from lignocellulosic materials. Lignocellulosic has the most potential material to provide a more economical feedstock as a result of its wide spread availability, sustainable production and low starting value ${ }^{2}$. The conversion of abundant lignocellulosic biomass to biofuels as transportation fuels presents a viable option for improving energy security and reducing greenhouse emissions ${ }^{3}$.

In order to improve the digestibility of lignocellulosic material and the yield of glucose in the enzymatic hydrolysis process, much research has been done to specifically investigate the optimization of the hydrolysis process. Discovery of an enzyme with high activity and a variety of things involved in the enzymatic hydrolysis process. Recent information has shown that an increase in the glucose production and digestibility of lignocellulose in the enzymatic hydrolysis process is strongly influenced by the pretreatment process to conversion lignocellulosic material for bioethanol production required three stage are pretreatment, hydrolysis/sacharification and fermentation. For sacharification using chemical methods, sometimes pretreatment process is eliminated. It could be due to some chemical substances may be used for simultaneous pretreatment and saccharification, for example sulfuric acid. Specifically for the development of pretreatment process for enhancing enzymatic sacharification and fermentation. The goal of the pretreatment process is to break down the lignin structure and disrupt the crystalline structure of cellulose, so that the acids or enzymes can easily access and hydrolyze the cellulose $^{3}$. The overall pretreatment process is expected to increase the yield of glucose and improve the digestibility of lignocellulosic materials on enzymatic hydrolysis.

Recently, the environment friendly approach has received attention as a pretreatment technique for enhancing enzymatic sacharification. Biological pretreatment be one option that could be considered to support the process of enzymatic hydrolsys. Several fungi are known to have the ability to degrade lignin such as Phanerochaete chrysosporium, Ceriporiopsis subvermispora, Plebia subserialis and Pleurotus ostreatus $^{4,5}$. The fungus has the ability to degrade lignin is widely used for various industrial applications, such as 
biopulping, animal feed and enzyme production. For the purposes of bioethanol production, lignin degradation targets different from other applications. In biopulping industry, the target maximum removal of lignin. While in the process of biological pretreatment, fungi can degrade lignin is expected to open access of cellulase enzymes and leaves ready hydrolyzed cellulose. Generally, biological pretreatment expected to increase the yield of enzymatic hydrolysis. The studies evaluated the effect of biological pretreatment on the production of glucose from enzymatic hydrolysis has been done by several researchers. Keller et al. ${ }^{6}$ found $36 \%$ of cellulose was converted to glucose after corn stover incubated for 29 days in Ceriporiopsis stercoreus. Taniguchi et al. ${ }^{5}$ found that $33 \%$ of cellulose in wheat straw was converted to glucose after 60 day pretreatment. Zhang et al. ${ }^{7}$ has studied pretreatment rice hull using Pleurotus ostreatus, the result showed maximum sugar yield of $49.6 \%$. Zhang et al. ${ }^{7}$ obtained sugar yield of $37 \%$ after bamboo culm after incubated using Coriolus versicolour. Shi et al. ${ }^{8}$ found improve cellulose conversion obtain $17.81 \%$ after pretreatment cotton stalks using Phanerochaete chrysosporium. Wan et al. ${ }^{9}$ studied biological pretreatment corn stover using Ceriporiopsis subvermispora, the result showed glucose yield of $37.15 \%$ after 35 day incubation of the fungus.

Previous research suggests that an increase in cellulose conversion and glucose yield after pretreatment lignocellulosic materials using various types of fungus. Therefore, in order to prepare water hyacinth as bioethanol feedstock, it require evaluation of the influence of fungal pretreatment on enzymatic hydrolysis. In addition, efforts are needed to improve the results of the glucose conditions by varying various biological pretreatment processes and studying its effect on glucose yield improvement. In addition, this research needs to study the effect of fungal pretreatment process conditions had on the increase in glucose results. In this study the influence of process conditions aims to increase the degradation of lignin and efforts to prevent the loss of cellulose and hemicellulose, which is expected to maximal glucose produced in the enzymatic hydrolysis process.

The water hyacinth is a lignocellulosic material, which has a high level of cellulose about $25 \%$ and hemicellulose about $35 \%$. Overall, the potential of water hyacinth can be converted into bioethanol reaching $60 \%$ in total.

To study the feasibility of applying biological pretreatment of water hyacinth using Phanerochaete chrysosporium, the effects of initial moisture content (IMC), material size, incubation time, addition of simple organic compound (in this case using molasses) and addition of co-factor $\mathrm{Mn}^{2+}$ on lignin degradation, hollocellulose degradation and enzymatic digestibility of water hyacinth were investigated.

\section{EXPERIMENTAL}

The water hyacinth (Eichhornia crassipes) was obtained from Yogyakarta, Indonesia. The water hyacinth stems and leaves are used. It was cut and dried under the sun for 4-6 days. Further the water hyacinth was dried using an oven with a temperature of $60{ }^{\circ} \mathrm{C}$ for $24 \mathrm{~h}$. Subsequently dried water hyacinth milled using a Ball mill. The variation in material size was obtained using a sieve with screen size $4,8,18$ and 40 mesh (equivalent to the size of 4.76-10, 2.38-4.76, 2.38-4.76, 1-2.38 and 0.426-1 mm, respectively). The water hyacinth used in this study has a composition of $7.98 \%$ lignin, cellulose 27.27 and $34.27 \%$ hemicellulose, $13.24 \%$ ash and other substances.

Simple organic compounds as nutrients in the pretreatment process using molasses. It is obtained from molasses in byproduct of sugar industry. The molasses has a glucose concentration of about $20 \%$. For various of additional of cofactor $\mathrm{Mn}^{2+}$ is used.

Phanerochaete chrysosporium used in this reseacrh was obtained from the collection of Department of Biology, Institute of Science and Research Indonesia. The enzyme for hydrolysis process was obtained from Suntaq cellulast International Limited Sqzyme CS P (Cellulase acid), activity of 10,000 U/g, Batch No. 1120604 CSP.

General procedure: $17.5 \mathrm{~g}$ of dried water hyacinth was filled to $500 \mathrm{~mL}$ bioreactor made of glass. It was then added with water obtain initial moisture content of 50, 60, 70 and 80 $\%$ (wet basis), respectively. Addition of molasses with various concentration of $0.5,15.2$ and $5 \%$, respectively. However for various addition of co-factor $\mathrm{Mn}^{2+}$, we used concentration of $\mathrm{Mn}^{2+}$ of $0.05,0.1,0.5$ and $1 \%$. After bioreactor filled with water hyacinth, water, molasses and a co-factor in accordance with the variation studied and then bioreactor was wrapped with the heat resistant plastic and put into autoclaved for 20 min at $121{ }^{\circ} \mathrm{C}$ and then cooled in a room temperature prior to inoculation.

Fungal preparation: The fungus Phanerochaete chrysosporium were prepared on Potatoe dextrose agar (PDA) medium in tilted position. The incubation process in the tilted PDA medium took 7 days. Phanerochaete chrysosporium cultured at the PDA were then innoculated and moved to the petridished and incubated at room temperature for another 7 days. This fungi preparation process were conducted prior to inoculation of water hyacinth in the bioreactor.

Biological pretreatment process: The fermentation was conducted in a series of bioreactor. In inoculation, Phanerochaete chrysosporium was added from petri dishes to bioreactor and incubated at a room temperature. It was incubated for 12 weeks and supported by the analysis that was conducted weekly.

To study the effect of water content to changes in the composition of water hyacinth and glucose yield, we use materials from 0.426 to $1 \mathrm{~mm}$ in size without the addition of molasses and a co-factor. Furthermore, to study the effect of the size of the material to changes in the composition of water hyacinth and the yield of glucose, then we use the water content showed maximum glucose yield of variations in initial moisture content. Some grain size used was 0.426 to $1 \mathrm{~m}, 1$ to $2.38 \mathrm{~mm}, 2.38$ to $4.76 \mathrm{~mm}$ and from 4.76 to $10 \mathrm{~mm}$. Furthermore, based on the observations of the previous variation, it will be determined that pretreatment time that show a significant decrease of lignin. Pretreatment period will be observed the effects on the addition of molasses and a co-factor $\mathrm{Mn}^{2+}$.

Enzymatic hydrolysis: Following the pretreatment of water hyacinth, sample was subjected to enzymatic hydrolysis. It was carried out for $5 \mathrm{~g}$ pretreated water hyacinth with cellulast 
enzyme. Enzymatic hydrolysis conditions were $\mathrm{pH} 5.5$, To obtain this condition, $150 \mathrm{~mL}$ of sodium acetate was added as buffer solution. Hydrolysis process was carried out for $72 \mathrm{~h}$ and sampling were performed every $24 \mathrm{~h}$.

The analysis of chemical composition of total dry weight, lignin, cellulose and hemicellulose were detemined using by Chesson methods ${ }^{11}$. Scanning clectrone microscopy (SEM) was used to analysis morphology structure of water hyacinth ${ }^{10}$. Somogyi-Nelson method was used to analysis the concentration of fermented sugar yield ${ }^{12}$.

\section{RESULTS AND DISCUSSION}

Effect of initial moisture content (IMC): After a pretreatment process using fungi, a change was seen to occur in the composition of the water hyacinth. Variations in pretreatment conditions also brought about changes in the composition of the water hyacinth. Initial moisture content is a condition that is essential in supporting the growth of the fungus and supporting the secondary metabolism in solid state fermentation ${ }^{13}$. In this study, we evaluated the effect of the initial moisture content on lignin degradation and glucose production. We used a material size of 0.426 to $1 \mathrm{~mm}$.

Furthermore, water was added to the water hyacinth with initial moisture contents of 50,60, 70 and $80 \%$. The results showed that there were differences in fungal growth, substrate degradation and glucose yield. Evaluation of the effects of varying the water content showed that the $50 \%$ IMC of the fungus can only survive for 7 weeks and then the fungus succumbed to deyhdration. In contrast, with $80 \%$ IMC the fungus did not grow at all. This was due to the fungus being unable to grow on the surface of the water hyacinth which are it almost totally submerged.

An IMC of $70 \%$ showed a significant decrease in the lignin. From the beginning of the incubation time a significant reduction of lignin was indicated from week 3 to week 7 . Furthermore, from week 8 until the end of the incubation, the decrease in lignin tended to slow down and stagnate. The most significant decrease in lignin, started at the beginning of incubation and continued until week 6 with the reduction of lignin reaching $51.55 \%$. Total reduction of lignin until the end of the incubation at $70 \%$ IMC, showed the highest lignin reduction reached $81.56 \%$. IMC of $60 \%$, the total decrease of lignin only reached $71.88 \%$. In addition to lignin degradation, for IMC of $70 \%$, the holocellulose (cellulose and hemicellulose) were hemicellulose reached 42.51 and $47.69 \%$, respectively. While the degradation of cellulose and hemicelluose only reached 37.49 and $41.87 \%$, respectively for IMC of $60 \%$.

The results of this study were in accord with research conducted by Asgher et al. ${ }^{13}$. The results showed that the highest lignin reduction came at an IMC of $70 \%$. Significant decrease in lignin is characterized by a high ligninase enzyme production $^{14}$. Shi et $a l .{ }^{8}$ showed that the degradation of lignin at an IMC of $75 \%$ indicated lignin degradation to be higher by $7 \%$ than that with a IMC of $65 \%$.

In the setting of water hyacinth as the raw material for bioethanol, lignin degradation targets do not have to reach the maximum, but it is necessary to consider the potential degradation of cellulose and hemicellulose. Degradation of lignin in the pretreatment process is expected only to open access of cellulase enzymes, which can lead to maximum glucose on enzymatic hydrolysis process. During the pretreatment process, holocellulose degradation occurs, then this may reduce the potential to produce glucose. Therefore these two things are necessary to be considered so that the glucose yield can be improved. To determine the effect of IMC on the yield of glucose on enzymatic hydrolysis process, the yield of glucose produced can be seen in Fig. 1.

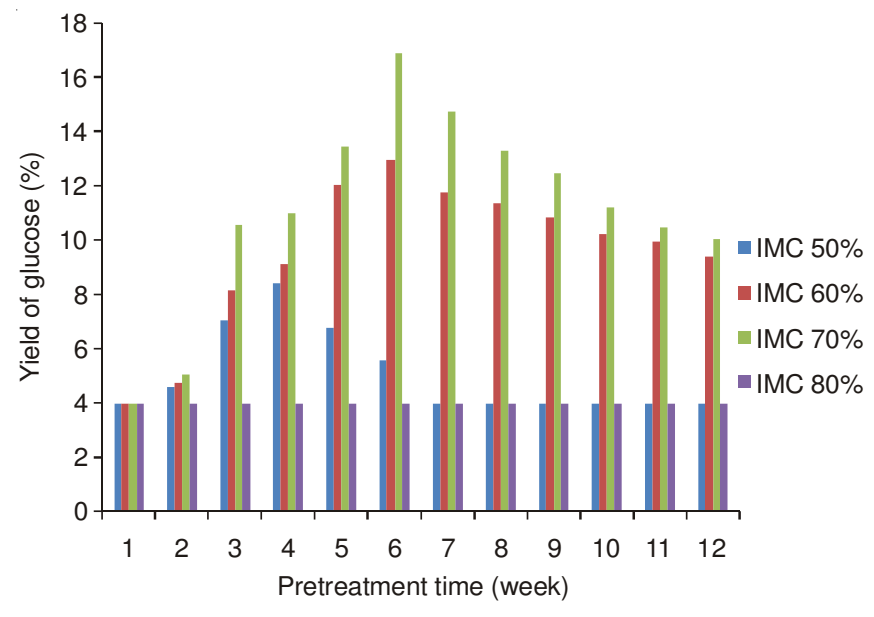

Fig. 1. Yield of glucose on enzymatic hydrolysis for all variations of IMC

Fig. 1 showed that a significantly higher glucose yield is achieved by $70 \%$ IMC, followed by $60 \%$ IMC. For $50 \%$ IMC, the yield of glucose showed an increase from the beginning of incubation until the $4^{\text {th }}$ week, then glucose yield decreased until the end of incubation. For $80 \%$ IMC, the yield of glucose from the beginning to the end of pretreatment remained the same. This is due to having no fungal growth at all, so that the glucose yield is the same as that of water hyacinths which did not undergo pretreatment.

For all IMCs, from the start of incubation until the $6^{\text {th }}$ week, the yield of glucose increased, then it showed a decrease until the end of the incubation. The increase of glucose yield was coupled with an increase in lignin degradation. Furthermore, glucose yield decreased with increasing holocellulose degradation. The highest yield of glucose was achieved by employing an $70 \%$ IMC at $6^{\text {th }}$ week. This is almost the same as the increase in lignin degradation during the $3^{\text {rd }}$ to $6^{\text {th }}$ week period of incubation. In this condition it is believed that significant destruction of lignin morphological structure had occurred, so that after pretreatment of the fungus and the enzymatic hydrolysis process had been performed and the yield of glucose increased significantly. In theory, the aim of the pretreatment process is to open access of cellulase enzymes to hydrolyze cellulose in the enzymatic hydrolysis process. A significant increase in glucose yield is predicted at the $6^{\text {th }}$ week, as there is a destruction of the structure and morphology of lignin which opens up access to the enzyme cellulase. These allegations need to be proven to ensure there is damage to the structure morphology of water hyacinth at the $6^{\text {th }}$ week. Therefore, we evaluated the morphological changes in the structure of water hyacinth using scanning electron nicroscopy (Fig. 2). 


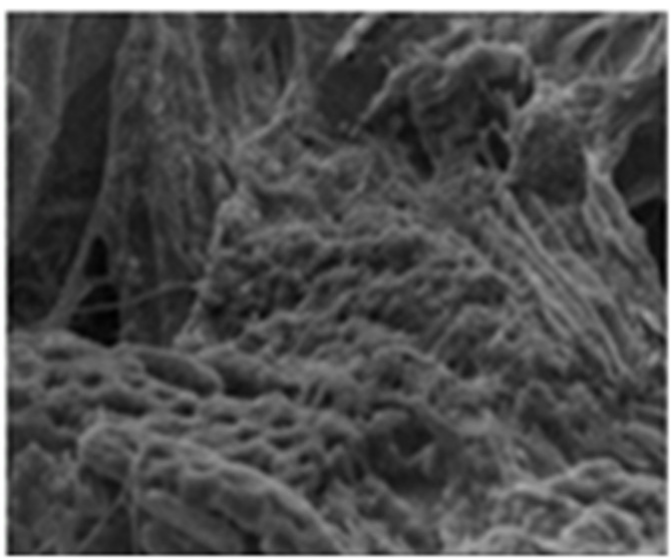

(a)

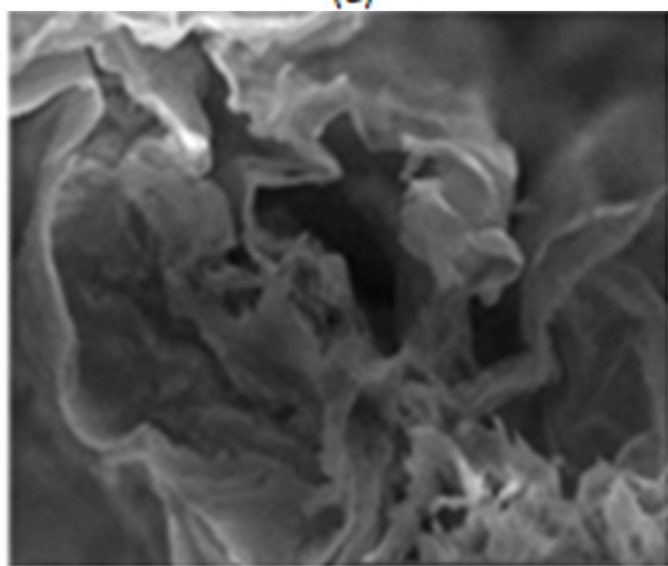

(c)

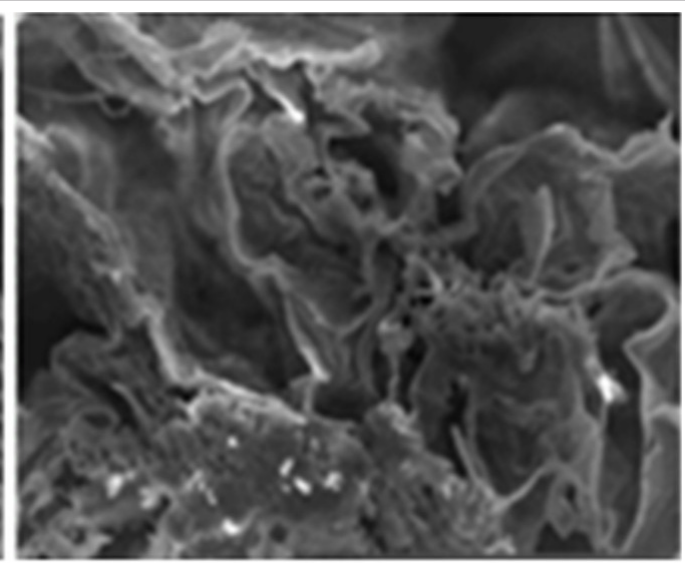

(b)

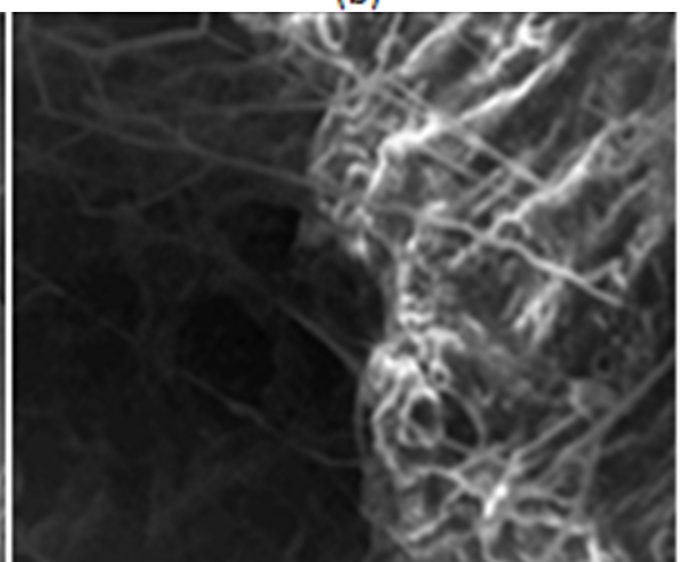

(d)

Fig. 2. Micrograph SEM analysis SEM before and after incubation for 6 weeks; a. Water hyacinth before incubation (at magnification $500 \mathrm{x}$ ), b. Water hyacinth after 6 weeks incubation (at magnification 500 x), c. Water hyacinth after 6 weeks incubation (at magnification $1000 \mathrm{x}$ ). d. Penetration of mycelia of Phanerochaete chrysosporium after 6 week incubation (at magnification $500 \mathrm{x}$ )

Evaluation of the microscale photo results from the SEM analysis showed that before pretreatment, surface of water hyacinths tended to show a relatively flat and irregular surface. After incubation with the fungus for 6 weeks, the surface of the water hyacinth appeared irregular and formed holes that indicated the presence of significant structural damage morphology. The damage is estimated to be the morphological structure of lignin breakdown which is the outer wall of the cell. Damage morphology of lignin structure is causes the open access of cellulase enzymes to hydrolyze cellulose in the enzymatic hydrolysis process. Verification of results of glucose yield in the enzymatic hydrolysis process support the allegation. Reduction of cellulose and hemicellulose is significant at $70 \%$ IMC, causing the overall glucose yield to remain low, reaching only $16.87 \%$. Modifications were then necessary to improve the yield of glucose in an attempt to achieve correct process conditions for preparation of the water hyacinth as a raw material for bioethanol production. Further studies of process conditions included :the influence of material size, the addition of molasses and the addition of co-factors $\mathrm{Mn}^{2+}$ to increase of lignin degradation and prevention of cellulose degradation in order to increase of digestibility and the yield of glucose in the enzymatic hydrolysis process.

Effect of material size of water hyacinth: Material size is a factor to be considered for its influence on fungal growth and lignin degradation. If the size of lignocellulosic materials is relatively small, it is expected to improve access of the fungus on the substrate, thereby increasing the degradation of lignin. Therefore, we evaluated the influence of the size of water hyacinth on the degradation of lignin and glucose yield during enzymatic hydrolysis. IMC of $70 \%$ will be fixed during process conditions to evaluate the effect of the size of water hyacinth ( 0.426 to 1,1 to $2.38,2.38$ to 4.76 and from 4.76 to $10 \mathrm{~mm}$ ) to increase lignin degradation and yield of glucose. The results showed almost no significant differences in lignin degradation for all sizes of materials, but that there was a tendency toward an increase in lignin degradation with larger material sizes. For material size of 4.76 to $10 \mathrm{~mm} 86.72 \%$ lignin degradation was reached.

It was demonstrated that the phenomenon differs from that of other materials such as sugarcane bagasse, cotton stalk, corn stover and other forms of lignocellulose. The study of fungal pretreatment on bagasse showed that a smaller size of sugarcane bagasse resulted in significant lignin degradation compared to a larger size. Reid et al..$^{12}$ observed that in aspen wood delignification of a small size, lignin degradation rate is higher than that of aspen wood of a larger size. This is in contrast to fungal pretreatment of water hyacinth. The experimental results showed that if the water hyacinth of a small size is added to water, it showed the phenomenon of agglomeration formation, which causes the fungus difficulty in penetrating the pile of water hyacinth. Therefore, the fungus grows more 
on the surface. Moreover, the agglomeration of water hyacinth will cause intra-particle space to be very small, affecting the diffusion of oxygen in the pile of water hyacinth. This condition affects the growth of fungi and the ability to access the oxygen inside the stack. Overall, the properties of water hyacinth agglomeration will affect the growth of fungi and degradation of lignin.

Production costs of bioethanol from lignocellulosic material are expected to be cheaper than those of fossil fuels. Reduction of size would prove expensive. Therefore, it is recommended to use relatively large material size to produce bio-ethanol from the water hyacinth. This is consistent with the findings that the large size gives great results in lignin degradation as well. Membrillo et al. ${ }^{15}$ evaluated material sizes of $0.92,1.68$ and $2.9 \mathrm{~mm}$ for the production of lignocellulytic enzymes. The highest of production of lignocellulytic enzyme occured using a material size of 2,9. Sarikaya and Ladisch ${ }^{16}$ found increased levels of lignin degradation by the larger of material size on the pretreatment of rapeseed using Pleurotus ostreatus.

Observation of holocellulose shows that there is a difference of cellulose and hemicellulose degradation for all material sizes. The results indicated that the greater the material size, the lower the holocellulose degradation, but the overall degradation of cellulose and hemicellulose is still relatively higher. The cellulose degradation reached 42.47, 52.79, 63.05 and $56.47 \%$ for sizes from 4.76 to $10 \mathrm{~mm}, 2.38$ to $4.76 \mathrm{~mm}$, from 1 to $2.38 \mathrm{~mm}$ and 0.426 to $1 \mathrm{~mm}$, respectively. Higher cellulose degradation causes a lower glucose yield in the enzymatic hydrolysis process.

The glucose yield results obtained during the evaluation of the influence of the size of water hyacinth can be seen in Fig. 3.

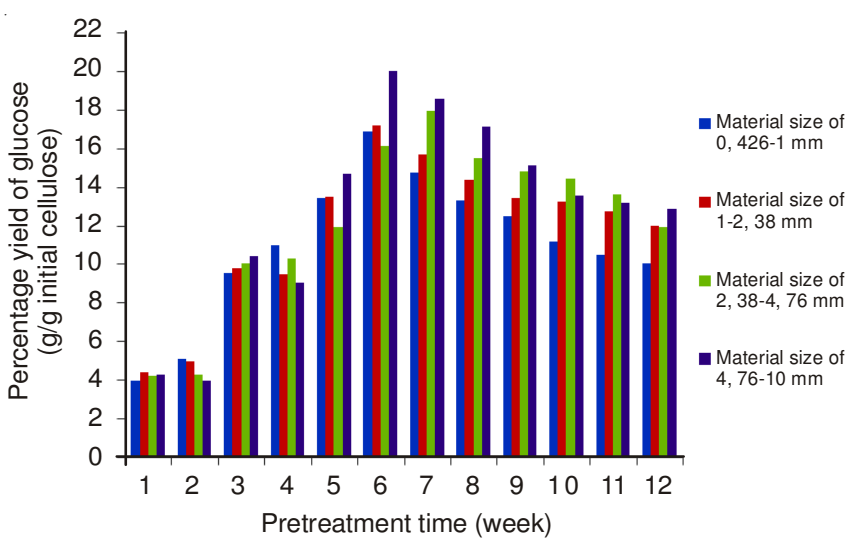

Fig. 3. Yied of glucose on various material size of water hyacinth

Fig. 3 shows that almost all sizes of material produced the highest glucose yield at the $6^{\text {th }}$ week, then decreased until the end of the incubation for 12 weeks. At the beginning of incubation glucose yield was shown to be almost the same, but in the middle of the incubation period, the yield of glucose with the larger material size was more significant than that with the smaller size. The highest yield of glucose reached $20.02 \%$ at material size $4.75-10 \mathrm{~mm}$ while for the other sizes yield of glucose reached $16.87,17.20$ and $17.89 \%$ for size of $2.38-4.76,1-2.38$ and $0.426-1 \mathrm{~mm}$, respectively. This result is thought to be influenced by lignin degradation, which suggests that larger material sizes also increase the amount of lignin being degraded. When an abundance of lignin is degraded, it will further expand the access of cellulase enzymes to hydrolyzed cellulose, which in turn leads to a higher of yield of glucose.

However, the highest glucose yield only reached $20.02 \%$, a result which is still considered very low. Therefore, development of research is still needed to increase the yield of glucose. The cellulose degradation occurs is still high at $42.47 \%$, it is necessary preventive efforts to control it. Efforts are being made to reduce the degradation of the cellulose is added simple carbon compounds. The compound used is molasses. Molasses contains glucose which is expected to be a major source of carbon and can initiate the growth of fungi. It is targeted to reduce the degradation of cellulose. The addition of molasses with $2 \%$ concentration showed encouraging results. Cellulose degradation decreased from 42.47 to $9: 14 \%$. The results of the evaluation of the yield of glucose showed a significant increase of 20.02 to $45.95 \%$. The yield of glucose is still considered not satisfactory, so still trying to increase the rate of degradation of lignin and increase the yield of glucose.

Effect of addition of Co-factor $\mathrm{Mn}^{2+}$ : Lignocellulosic materials and fungi used have different characteristics, so the glucose yield results differ. In general, the yields of glucose in this study are still relatively low. These results still do not meet the target for preparing water hyacinth as a bioethanol feedstock. Regarding the prevention of degradation of cellulose playing an important role in improving the yield of glucose are considered to be correct. The results of the study with the addition of molasses with a $2 \%$ concentration can increase glucose yield from 20.02 to $43.91 \%$. This suggests that the increase in glucose yield reached more than 2-fold after $2 \%$ molasses was added. This result is still not considered satis-factory.

We focused on the purpose of the pretreatment process. Pretreatment aims to degrade lignin and open access of cellulase enzymes. Based on this, we tried to find solutions to increase the degradation of lignin. Ligninolitic enzyme is an enzyme produced by the fungus to degrade lignin. The enzyme is composed of lignin peroxidase (LIP) enzyme, manganesse peroxidase $(\mathrm{MnP})$ enzyme and laccase. To increase the activity of this enzyme another compound may be added called cofactor. These co-factor compounds may be metal ions which can help the activity of the enzymes to degrade lignin. We tried to observe the effect of the addition of co-factor $\mathrm{Mn}^{2+}$ known to increase the activity of the MnP enzyme. The addition of co-factor $\mathrm{Mn}^{2+}$ is expected to increase the speed of lignin degradation and to produce lignin systemic damage so as to provide a space as wide as possible to allow the enzymes to access the cellulose-cellulase in the enzymatic hydrolysis process.

The addition of a co-factor with a concentration of $0.5 \%$ at the beginning of the pretreatment results in an increase in glucose yield in enzymatic hydrolysis process which can be seen in Fig. 4.

In Fig. 4, a significant increase in glucose yield can be seen when co-factor $\mathrm{Mn}^{2+}$ is added. Without the addition of co-factor $\mathrm{Mn}^{2+}$, glucose yield reached only $43.97 \%$, whereas when co-factor $\mathrm{Mn}^{2+}$ was added at a concentration of $0.5 \%$, 


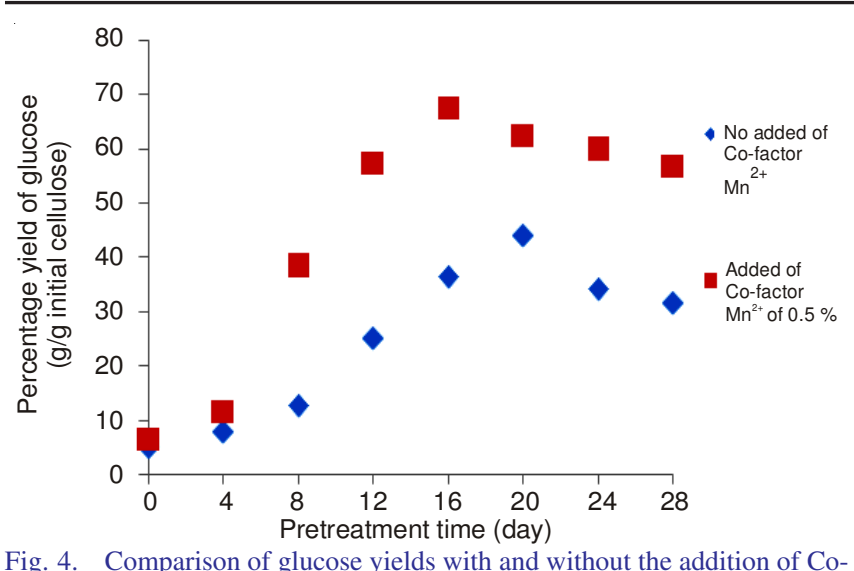

Fig. 4. Comparison of glucose yields with and without the addition of Cofactor $\mathrm{Mn}^{2+}$

the yield of glucose increased to $67.66 \%$ or an increase of approximately $23.69 \%$ over the 16 days of incubation with the fungus. This means that the time of pretreatment is shortened by 4 days. This relatively high increase was caused by the addition of co-factor $\mathrm{Mn}^{2+}$ with the appropriate concentration to increase the production of ligninolitic enzymes. These enzymes provide optimum lignin degradation and can open up broad access to allow the cellulase enzymes to hydrolyze cellulose during the enzymatic hydrolysis process. Glucose yield reached $67.66 \%$ This means an increase of more than $60 \%$ if the water hyacinth in pretreatment with fungi is compared to water hyacinth without pretreatment processes which produces less than $5 \%$ glucose. The success in improving the yield of glucose in this study is expected to stimulate and encourage the development of other lignocellulosic materials to be used as raw material for bioethanol production by optimizing the biological pretreatment process using fungi. This result is not much different from the research conducted by Isroi et $a l .{ }^{17}$, who conducted research into the addition of co-factor $\mathrm{Mn}^{2+}$ and co-factor $\mathrm{Cu}^{2+}$ in the pretreatment of oil palm empty fruit bunch (TKKS) using the fungus Pleurotus Ostreatus. The results showed that the digestibility of TKKS during the hydrolysis process reaches $55.67 \%$ when co-factor $\mathrm{Mn}^{2+}$ was added and reached $60.27 \%$ with the addition of cofactor $\mathrm{Cu}^{2+}$.

\section{Conclusion}

Fungal pretreatment process conditions have an important role to play in the production of maximum lignin, the prevention of holocellulose degradation and the increase of glucose yield during the enzymatic hydrolysis process. An IMC of $70 \%$ can produce maximum degradation compared to other IMC conditions. Lignin degradation reached $51.55 \%$ in the $6^{\text {th }}$ week of incubation of water hyacinth with Phanerochaete chrysosporium. SEM analysis results indicated the presence of water hyacinth morphological damage occurring in the $6^{\text {th }}$ week, so the pretreatment time can be shortened. The evaluation of the size of the material shows that the larger the size of grain the greater the increase in lignin degradation. The material size that gives maximum lignin degradation is shown to be the largest size i.e. 4.76 to $10 \mathrm{~mm}$. Differences in material size are very influential in the degradation of holocellulose. High holocellulose degradation may result in a low yield of glucose, which may only reach $20.02 \%$. Prevention of degradation of cellulose can be done by adding a simple carbon compound such as molasses. The addition of molasses at a concentration of $2 \%$ can lower cellulose degradation to reach $21 \%$ and an increase in glucose yield which can reach $43.91 \%$. The addition of co-factor $\mathrm{Mn}^{2+}$ at a $0.5 \%$ concentration can increase glucose yield to reach $66.67 \%$ and shorten the pretreatment time to 16 days.

\section{ACKNOWLEDGEMENTS}

The authors thank to Directorate General of Higher Education Indonesia (DP2M DIKTI) for giving financial support of this work through research Grant for student of Doctoral Program "Hibah Disertasi Doktor 2010", Gadjah Mada University, Yogyakarta.

\section{REFERENCES}

1. N. Mosier, R. Hendrickson, N. Ho, M. Sedlak and M.R. Ladisch, J. Biotechnol., 96, 1986 (2005).

2. http://feedstockreview.ornl.gov/pdf/billion_ton_vision.pdf.

3. P. Kumar, D.M. Barrett, M.J. Delwiche and P. Stroeve, Ind. Eng. Chem. Res., 48, 3713 (2009).

4. A.I. Hatakka, Eur. J. Appl. Microbiol. Biotechnol, 18, 350 (1983).

5. M. Taniguchi, H. Suzuki, D. Watanabe, K. Sakai, K. Hoshino and T. Tanaka, J. Biosci. Bioeng., 100, 637 (2005).

6. F.A. Keller, J.E. Hamilton and Q.A. Nguyen, Appl. Biochem. Biotechnol., 105, 27 (2003).

7. X. Zhang, H. Yu, H. Huang and Y. Liu, J. Int. Biodeter. Biodegrad., 60, 159 (2007).

8. J. Shi, M.S. Chin and R.R. Sharma-Shivappa, Bioresour. Technol., 99, 6556 (2008).

9. C. Wan and Y. Li, Bioresour. Technol., 101, 6398 (2010).

10. A.B. Datta, A. Betterman and T.K. Kirk Appl. Environ. Microb, 57, 1453 (1991).

11. J.P. Marais, J.L. de Wit and G.V. Quicke, Anal. Biochem., 15, 373 (1966).J

12. I.D. Reid, J. Enzyme Microbial Technol., 11, 786 (1989).

13. M. Asgher, M. Asad and R. Legge, World J. Microbiol. Biotechnol., 22, 449 (2006).

14. E. Hemiati, D. Mangunwidjaja, T.C. Sunarti, O. Suparno and B. Prasetya, J. Litbang Pertanian, 29, 1 (2010).

15. I. Membrillo, C. Sánchez, M. Meneses, E. Favela and O. Loera, Bioresour. Technol., 102, 1581 (2011).

16. A. Sarikaya and M.R. Ladisch, Appl. Biochem. Biotechnol., 82, 1 (1999).

17. Isroi, Dissertation Summary as Requirement for Doctoral Degree Program Study of Biotechnology Gadjah Mada University, Yogyakarta, Indonesia (2013). 